\title{
Cultura política e teoria DA DEMOCRACIA: IMPLICAÇÕES EMPÍRICAS DE UM DEBATE TEÓRICO
}

\author{
Ednaldo Aparecido Ribeiro
}

Professor de Ciência Política das Faculdades Integradas de Palmas/PR

E-mail: ednaldorib@yahoo.com.br

\section{Resumo}

O presente artigo pretende discutir a problemática relação entre a teoria contemporânea da democracia e os estudos sobre cultura política, a partir de um estudo de caso sobre as orientações políticas subjetivas dos membros do Conselho de Saúde da Região Sul de Londrina (CONSUL), uma organização popular existente na cidade de Londrina no interior do Paraná. Pretendemos defender a tese de que as conclusões suscitadas por um estudo acerca das orientações políticas subjetivas de subgrupos da comunidade nacional tendem a ter suas conclusões radicalmente alteradas em virtude de um posicionamento diante do debate teórico-conceitual sobre a questão da democracia.

Palavras-chave: democracia; cultura política; participação; conselhos.

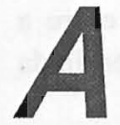

consolidação da democracia brasileira tem sido, nos últimos anos, um dos temas mais estudados por pesquisadores das ciências sociais. Isto pode ser explicado em parte pela novidade que tal regime representa em nossa história política, marcada por longos períodos autoritários. Dentre os vários enfoques presentes nestas investigações, podemos destacar o crescente interesse pela análise da relação entre as orientações políticas subjetivas dos indivíduos e o funcionamento deste sistema. Estamos nos referindo aos estudos sobre a cultura política nacional que tem sido produzidos nos últimos anos.

Neste artigo, pretendemos apresentar um conjunto de reflexões sobre os pressupostos que têm orientado estas investigações quando seus universos de análise são subgrupos da comunidade política nacional. Mais especificamente vamos analisar a relação entre o 
conceito de democracia utilizado em estudos sobre cultura política e as conclusões de tais investigações.

Para tanto, nos valeremos dos resultados de uma pesquisa empírica junto ao Conselho de Saúde da Região Sul de Londrina (CONSUL), uma organização popular voltada para o acompanhamento e fiscalização da política de saúde implementada neste município do interior do estado do Paraná. Pretendemos demonstrar, através da apresentação dos dados sobre a cultura política dos membros deste conselho, que a adoção de um conceito específico de democracia, entre os disponíveis na moderna teoria política, tende a alterar significativamente as conclusões do investigador não apenas sobre as orientações subjetivas dos indivíduos que compõem o seu campo de pesquisa, mas também sobre a consolidação do regime no qual se inserem.

Para alcançar nosso objetivo dividimos o presente artigo em três seções. Inicialmente, tratamos de discutir rapidamente o conceito de democracia presente na teoria da democracia contemporânea, nos concentrando-nos especificamente no debate travado entre realistas e participacionistas.

Na segunda seção apresentamos os dados empíricos sobre a cultura política dos participantes do Consul que, como afirmamos, pode ser caracterizado como um subgrupo político.

Na última parte do trabalho, através de questões suscitadas pelos dados empíricos, nos dedicamos a analisar a relação entre a teoria da cultura política aplicada a estudos de subgrupos e a teoria da democracia contemporânea.

\section{A democracia em questão}

É bastante óbvio que a palavra democracia tem sido utilizada para designar um conjunto bastante díspar de situações e instituições políticas sem que os interlocutores tenham uma real compreensão sobre seus significados.

Até mesmo entre debatedores pretensamente privilegiados, como os que se encontram no interior da academia, demonstra-se esta falta de sincronismo quando se trata de denominar este "ser" que em muitos 
casos nos parece desprovido de forma e conteúdo. Prova disto é o flagrante desacordo sobre se este ou aquele país cumpre as exigências necessárias para ser enquadrado como uma democracia ou não.

Diante desta profusão de significados e critérios sobre o que é uma democracia ou sobre quais são os elementos que devem estar presentes em uma sociedade ou Estado democrático, acreditamos que todo o esforço de precisão seja muito bem vindo.

Dentro desta questão, nossa atenção se volta especialmente sobre uma tensão que se construiu dentro da teoria política contemporânea, protagonizada por duas grandes correntes que se dedicam a interpretar o fenômeno democrático e que podem orientar diferentes perspectivas de análise em estudos sobre cultura política: a perspectiva realista e a participacionista. ' Como pretendemos demonstrar, a adoção de uma ou outra perspectiva tende a alterar significativamente a interpretação do investigador sobre os dados coletados em uma pesquisa sobre as orientações políticas subjetivas em grupos.

Começando pela corrente realista, não poderíamos deixar de nos remeter às contribuições de Joseph Schumpeter. Em Capitalismo, Socialismo e Democracia, este economista realiza uma incursão no campo da ciência política, ao estabelecer os fundamentos para uma análise sobre o regime político democrático tendo como ponto de partida a observação e descrição do que realmente pode ser observado na realidade concreta.

Através deste expediente empirista, Schumpeter nos propõe uma definição de democracia que rompe com o ideal clássico ligado à etimologia da palavra. A democracia deixa de ser entendida como o "governo do povo", para ser entendida como um método ou procedimento de escolha de lideranças, que devem conduzir os complexos assuntos públicos das sociedades modernas.

De acordo com este autor, na teoria clássica, a questão fundamental ou o critério principal para a definição de um regime como

\footnotetext{
I Ao denominarmos estas duas perspectivas como "grandes correntes" pretendemos destacar a profunda arbitrariedade que está presente na tentativa de agrupar toda a imensa produção sobre a questão democrática em apenas dois grupos. Entretanto, ainda que artificial, este recurso nos parece ser analiticamente viável na ausência de outra forma de classificação mais precisa.
} 
democrático era a realização da vontade geral, que implementaria o ideal de deixar ao povo a atribuição de decidir sobre os assuntos políticos mais relevantes.

Em oposição a esta concepção, por acreditar ser inviável uma proposta que depende de elementos inexistentes, como uma "vontade geral" ou "bem comum", Schumpeter inverte os elementos desta equação política.

A eleição dos representantes que deveriam tomar as decisões, que na teoria clássica era um elemento secundário, passa a ocupar o papel de protagonista na definição do que é e do que não é uma democracia. Dessa forma, o povo soberano do modelo anterior tem como principal missão "[...] formar um governo, ou corpo intermediário, que por seu turno, formará o executivo nacional, ou governo[...]" (SCHUMPETER, 1961, p. 327).

A democracia, passa a ser entendida, então, como um sistema de instituições que regula uma competição entre os indivíduos pelos postos deste corpo intermediário que irá tomar realmente as decisões políticas.

O que definiria um país como "de regime democrático" ou não, seria a existência de um determinado método ou procedimento, através do qual os homens se lançariam à busca de votos, em uma competição regulamentada por algumas regras previamente definidas e aceitas por todos.

Esta definição inaugurada por Schumpeter provocou um grande debate no interior da ciência política, gerando muitos adeptos e críticos. Entre os que acolhem esta corrente e contribuem para ela podemos citar R. Dahl, M. Olson, A. Downs, G. Sartori, além de outros. Não se trata de afirmar que estes autores adotam integralmente e de maneira idêntica a postura de Schumpeter, mas é incontestável que em todos eles verifica-se uma ênfase nos procedimentos institucionais de caráter representativo que existem nas democracias ocidentais contemporâneas.

Esta perspectiva empírica da democracia acabou gerando uma série de críticas formuladas por autores que afirmam a necessidade de ir além da descrição e da constatação sobre a natureza da moderna democracia. 
Apesar de uma considerável diversidade interna, esta segunda corrente. que agui chamaremos participacionista, tem como um dos scus pontos centrais a construção de modelos sobre como uma verdadeira democracia deveria ser, além, é claro, de apontar algumas pistas sobre qual o caminho que pode conduzir à sua construção.

Peter Bachrach (1967), em seu livro The Theory of Democratic Elitism - a critique, tece uma crítica ao que denomina de "elitismo democrático" construindo um modelo alternativo, que entende a participação como algo possível na democracia contemporânea. ${ }^{2}$

Para este autor, justamente no argumento elitista, que apela para a necessidade de eficiência e conhecimentos técnicos, para a resolução dos problemas da moderna sociedade, é que se encontra o grande problema da perspectiva realista. Isto porque, ao negar a possibilidade da interferência do cidadão comum, a corrente elitista democrática estaria também considerando como impossível o crescimento humano através da participação nos assuntos públicos relevantes.

A proposta defendida por este participacionista afirma que a democracia deve ser entendida de uma maneira bidimensional, ou seja, como meio para alcançar um fim (bens e serviços), mas também, como processo de participação, através do qual o homem comum poderia desenvolver habilidades intelectuais e morais.

Esta dupla dimensão é encarada pelos elitistas democratas como irrelevante em uma sociedade industrial, na qual as decisões importantes devem ser necessariamente tomadas por uma minoria dirigente.

A resposta, formulada por Bachrach (1967, p.96-97) a esta incontestável afirmação realista é a seguinte: admitindo-se que no nível nacional a participação é bastante limitada, isto não pode ser transposto imediatamente para níveis intermediários e inferiores de tomada de decisões políticas, que estão mais próximas e afetam primeiramente a vida do homem comum .

O que impediria os elitistas democráticos de visualizar a possibilidade da participação nestes níveis da atividade política é justamente o entendimento sobre o que chamam de política.

2 Além deste autor, vários outros compõem o núcleo participacionista da teoria da democracia contemporânea, entre os quais merecem destaque Carole Pateman, Chantal Mouffe e C.B. Macpherson. 
Ao partir de um conceito de política restrito que a entende apenas como composta por aquelas ações, que se situam no centro do poder do Estado e de suas instituições principais, estes cientistas estariam demonstrando o caráter ideológico de suas proposições.

Se as organizações privadas, ou ao menos as mais poderosas, forem consideradas esferas da política, podemos entendê-las como arenas em que uma expansão da igualdade de poder através da participação pode ocorrer, sobretudo através de uma alteração radical na sua estrutura hierárquica.

A base da proposta de Bachrach está fundamentada na discussão desenvolvida por J.S. Mill sobre a dimensão pedagógica da política, ou seja, a afirmação de que a participação nos assuntos públicos leva ao desenvolvimento das potencialidades dos cidadãos (MILL, 1981).

Diante da necessidade de escolher entre " $[. .$.$] a theory which is$ normatively sound but unrealistic, or a theory which is realistic but heavily skewed toward elitism [...]", o autor acredita ter formulado um terceiro caminho baseado no autodesenvolvimento do indivíduo na sociedade industrial (BACHRACH, 1967, p. 99).

Tal concepção se assenta sobre o pressuposto de que a maioria dos indivíduos tem um duplo interesse na política, um que diz respeito aos fins que necessita alcançar, e outro decorrente do próprio processo que pode levar ao desenvolvimento de sua auto-estima e do crescimento de sua personalidade pela participação na tomada de decisões relevantes.

Implica, também, uma compreensão da política que vai além da compartilhada pela concepção realista exposta acima, envolvendo várias outras áreas da vida social que estão abertas, de acordo com o autor, para a ampliação da participação na tomada de decisões, em especial as grandes corporaç̃es privadas.

Os indivíduos se comportariam de forma apática com relação ao sistema político propriamente dito por considerar estes assuntos muito distantes de sua realidade, o que não aconteceria com os assuntos mais ordinários que dizem respeito a sua vida cotidiana, como aqueles que se dão nas fábricas, nos escritórios, etc. A experiência de participação nestes locais próximos poderia levar a uma alteração no comportamento destes indivíduos com relação aos níveis superiores.

Como podemos identificar, esta proposta é marcada por uma 
crítica bastante perspicaz e coerente aos paradoxos de uma tentativa de conciliação entre as estruturas democráticas e o elitismo político. Quanto a isso, parece-nos que o trabalho é de fundamental importância para o desenvolvimento da teoria democrática como um todo, para além da separação, entre realismo e participacionismo.

Este debate, como já antecipamos na Introdução deste artigo e desenvolveremos abaixo, produz sérias consequiências no campo empírico, em especial em estudos sobre orientações políticas subjetivas.

\section{Valores e instituições democráticas}

Neste momento apresentaremos os dados ${ }^{3}$ relativos a cultura política dos membros do CONSUL, para depois analisarmos a relação entre as possíveis conclusões suscitadas pela pesquisa empírica e os pressupostos teóricos que a orientam.

Sendo assim, tratamos inicialmente de avaliar o conjunto das percepções dos membros do CONSUL, tendo em vista a identificação de sua adesão ou não aos valores e instituições democráticas, para depois propor uma interpretação alternativa acerca dos resultados.

Um dos indicadores clássicos em estudos sobre cultura política é sem dúvida o que pretende medir o grau de interesse que um determinado grupo possui em relação aos assuntos políticos ${ }^{4}$. Como exemplo podemos citar a pesquisa realizada em nível nacional por Moisés (1995, p.124) que atesta uma mudança em curso na cultura política brasileira através da comparação, entre outras variáveis, do grau de interesse por política manifestado pelos entrevistados. Os dados apresentados mostram que este interesse tem crescido desde o desenvolvimento das instituições democráticas nacionais na década de 80 , chegando a atingir em 1993 a marca de $68,7 \%$, contra os $60,5 \%$ registrados em 1989.

\footnotetext{
${ }^{3}$ Os dados foram coletados através da proposição de um questionário com cinquienta e sete questões fechadas a vinte e seis membros da diretoria do Consul. Após a coleta estes dados foram processados através do programa SPSS for Windows 9.0.

+ No estudo pioneiro sobre cultura política (Almond; Verba, 1989), esta é um dos primeiros indicadores para a definição da cultura política de uma população.
} 
No caso do nosso estudo, o pressuposto que orientou a formulação desta questão é de que indivíduos interessados por política tendem a engajar-se de maneira mais ativa nas discussões públicas, o que favorece o desenvolvimento da democracia.

Sendo assim, o quadro por nós encontrado no que diz respeito ao grupo de ativistas do CONSUL parece caminhar na direção dos dados nacionais. Como não poderia deixar de ser, uma vez que se trata de um grupo com fins eminentemente políticos e que, como veremos no decorrer desta seção, são orientados por uma ideologia participacionista, obtivemos como percentagem acumulada $88,4 \%$ (Tabela 1) de respostas entre as opções "se interessa muito" e "se interessa".

\begin{tabular}{|c|c|c|}
\hline \multicolumn{3}{|c|}{$\begin{array}{l}\text { "De um modo geral, em que medida o(a)Sr.(a) } \\
\text { se interessaporpolítica?" }\end{array}$} \\
\hline RESPOSTAS & $\%$ & $\mathbf{N}$ \\
\hline Se interessamuito & 69,2 & 18 \\
\hline Seinteressa & 19,2 & 5 \\
\hline Se interessapouco & 11,5 & 3 \\
\hline Nãose interessa & 0,0 & 0 \\
\hline TOTAL & 100,0 & 26 \\
\hline
\end{tabular}

Ainda tratando da questão da adesão a valores democráticos, acreditamos que seja interessante verificar em que medida este grupo adere à outra dimensão da cultura política nacional bastante persistente: o elitismo.

Lima e Cheibub (1996), realizando um estudo junto a elites em nível nacional comprovam a tese de que, a despeito de algumas alterações significativas, nossa cultura política ainda é impregnada de elitismo e de uma visão hierárquica da vida social.

Os seus entrevistados revelaram um certo consenso no que se refere à aceitação da dimensão institucional da democracia, ou seja, o nível de confiança e a legitimidade se mostraram bastante elevados, o que vindo de uma elite estratégica é muito importante para o processo de consolidação do regime.

O problema surgiu quando os pesquisadores partiram para a 
ancílise sobre a associação desta adesão institucional com a incorporaçaio de normas e valores democráticos, como o ideal de igualdade. Ayui se reselou que, apesar de portadores de uma cultura política democrálica no que se refere às instituições, no que tange aos valores que possuem uma base mais societal, como elitismo, igualdade, distributivismo e outras, estas elites compartilham de uma posição bem menos favorável (LIMA; CHEIBUB, 1996, p. 101).

Neste sentido, procuramos, através de algumas questões agregadas, identificar qual o posicionamento dos membros do Conselho para com esta dimensão, concentrando- nos especialmente sobre a oposição entre elitismo e igualitarismo.

Com esta intenção, inicialmente formulamos a seguinte frase para que as pessoas se posicionassem: "Ao tomar uma decisão, o Governo deve ouvir apenas a opinião das pessoas que têm conhecimento sobre o assunto."

A grande maioria dos entrevistados, $80,8 \%$, optou pelo "discorda" e "discorda muito", o que nos sugere uma tendência contrária ao elitismo e a adoção de um princípio igualitário no que diz respeito ao processo de tomada de decisões.

A segunda e a terceira questões sobre este ponto procuraram especificar a adesão ao elitismo no que se refere à restrição de direitos políticos, tendo como critério a escolaridade. Como demostram as tabelas abaixo (Tabelas 2 e 3), também com respeito a estas questões mais diretas e específicas, encontramos respostas que questionam o elitismo. Apesar do caráter extremado do elitismo que a questão se propõe a medir, acreditamos que seja relevante esta relativa negação do critério de escolaridade como definidor de direitos políticos formais.

\begin{tabular}{|c|c|c|}
\hline \multicolumn{3}{|c|}{$\begin{array}{l}\text { "Na opinião do Sr.(a)., apenas os dotados deescolaridade } \\
\text { suficiente deveriam podervotar?" }\end{array}$} \\
\hline RESPOSTAS & $\%$ & $\mathbf{N}$ \\
\hline Sim & 12,0 & 3 \\
\hline Năo & 88,0 & 22 \\
\hline TOTAL & 100,0 & 25 \\
\hline
\end{tabular}




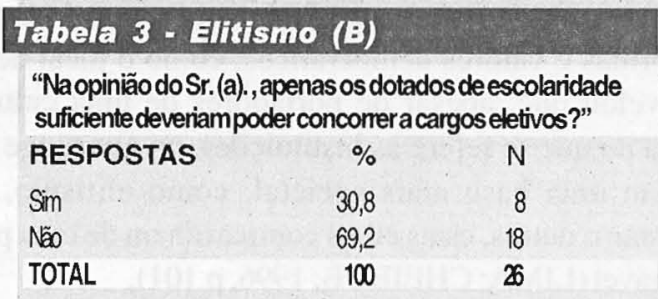

Estes resultados se confirmam quando entramos no campo da avaliação dos entrevistados sobre a capacidade cognitiva da maioria da população para participarem de atividades políticas. Como podemos identificar abaixo, a maioria dos membros do conselho acredita na capacidade da população para interferir na condução dos assuntos públicos.

\begin{tabular}{|c|c|c|}
\hline \multicolumn{3}{|c|}{$\begin{array}{l}\text { Tabela } 4 \text { - Avallagâo Sobre a Capacida- } \\
\text { de }\end{array}$} \\
\hline \multicolumn{3}{|c|}{$\begin{array}{l}\text { "O(A)Sr.(a)concorda ou discorda da seguinte afirmação: A } \\
\text { grandemaioriada populaçãonãotem como influir napolítica. } \\
\text { Istoé coisa para os entendidos eos políticos." }\end{array}$} \\
\hline RESPOSTAS & $\%$ & $\mathrm{~N}$ \\
\hline Concordamuito & 19,2 & 5 \\
\hline Concorda & 7,7 & 2 \\
\hline Não concorda, nem discorda & 3,8 & 1 \\
\hline Discorda & 53,8 & 14 \\
\hline Discordamuito & 15,4 & 4 \\
\hline TOTAL & 100,0 & 26 \\
\hline
\end{tabular}

A fim de confirmar esta tendência, apresentamos também a seguinte afirmação, "Ao tomar uma decisão, o Governo deve ouvir apenas a opinião das pessoas que têm conhecimento sobre o assunto", para a qual recolhemos um percentual acumulado de 80,8 entre as opções "discorda" e "discorda muito".

Os dados apresentados até este momento, sugerem a interpretação de que as orientações políticas subjetivas da maioria dos membros do Conselho em questão são relativamente congruentes com 
o regime político democrático, pois estes se manifestaram interessados por política, e relativamente anti-elitistas.

Resta, entretanto, após identificar o posicionamento do grupo em relação a esta dimensão abstrata do regime, realizar a sua comparação com a tendência à participação efetiva destes atores em atividades políticas que extrapolam os limites do Conselho do qual são membros.

Neste item, mais de $60 \%$ dos entrevistados, como mostra a Tabela 5, afirmaram ter participado ativamente nas últimas campanhas eleitorais, através de trabalho voluntário para um ou para outro candidato ou partido político, além de participarem assiduamente de comícios e debates públicos entre os concorrentes.

\section{Tabela 5 - Participaçáo Política}

\begin{tabular}{l|rr|rr} 
PERGUNTA & \multicolumn{2}{|c|}{ SIM } & \multicolumn{2}{|c}{ NÃO } \\
Compareceu aalgum comicio & $\%$ & N & $\%$ & N \\
Fezalgum trabalho gratuito para algum candidato ou partido. & 76,9 & 20 & 23,1 & 6 \\
Colocou cartazes em sua casa, automóvel ou local de trabalho. & 76,1 & 19 & 26,9 & 7 \\
Compareceua alguma reunião para ouvirdebates. & 73,1 & 19 & 23,1 & 6 \\
& & & 26,9 & 7
\end{tabular}

Nota: Em relação à ụitima campanha eleitoral

Além do que sugere a tabela, a análise dos momentos mais relevantes nos últimos dez anos na política municipal de saúde do município de Londrina, mostra que os membros deste conselho tiveram um papel fundamental como ativistas políticos engajados em reivindicações e manifestações coletivas, para além dos períodos eleitorais.

Através destes dados, devemos levar em consideração que, em se tratando do grupo em questão, o interesse subjetivo por política tende a manifestar-se em uma postura ativista.

O caráter democrático e participacionista que começamos a descrever acima também se manifesta quando nos debruçamos sobre a questão da eficácia política subjetiva dos membros do grupo, ou seja, a percepção dos atores políticos com relação ao seu próprio papel dentro do sistema político. Trata-se, portanto, de uma auto-avaliação realizada pelos indivíduos sobre sua atuação diante dos fatos e objetos 
políticos, em especial, sobre a sua capacidade de influenciar a tomada de decisões políticas (ALMOND; VERBA, 1989).

Confirmando a adesão aos valores próprios de uma postura ativista, encontramos níveis elevados de eficácia política subjetiva, o que diferencia em muito este grupo de ativistas do conjunto da população brasileira, como nos mostra MOISÉS (1995, p.207) em sua pesquisa, na qual $57,8 \%$ dos entrevistados acreditavam não influenciar a política.

Este número expressivo corrobora as afirmações acerca da chamada passividade do brasileiro que, de acordo com José Murillo de Carvalho "[...] é a própria definição do não-cidadão, do súdito que sofre, conformado e alegre, as decisões do soberano [...]", algo que pode ser entendido como uma auto-avaliação negativa no campo da ação política, que pode colocar em risco o regime democrático, como já apontamos nas seções anteriores (CARVALHO,1999, p.36).

Como os números a seguir demonstram (Tabela 6), este grupo de indivíduos tem em alta conta sua capacidade de influenciar a tomada de decisões políticas. Este índice seria positivo para a consolidação de uma democracia, pois indivíduos que se sentem importantes para o sistema, tendem a defendê-lo em situações de risco.

\begin{tabular}{|c|c|c|}
\hline \multicolumn{3}{|c|}{$\begin{aligned} \text { Tabela } 4 \text { - Auto-Avaliaģão Sobre } \\
\text { a Capacidade de Influenciar }\end{aligned}$} \\
\hline \multicolumn{3}{|c|}{$\begin{array}{l}\text { "Comoum 'cidadãocomum', o(a)Sr(a)acreditaque influen- } \\
\text { ciaapolítica?" }\end{array}$} \\
\hline RESPOSTAS & $\%$ & $\mathrm{~N}$ \\
\hline Sim & 57,7 & 15 \\
\hline Emparte & 30,8 & 8 \\
\hline NẼ & 11,5 & 3 \\
\hline TOTAL & 100,0 & 26 \\
\hline
\end{tabular}

A explicação para essa avaliação positiva sobre si mesmo, assim como o seu oposto, ou seja, um sentimento de ineficácia política, de acordo com a teoria da cultura política, é consequiência de um processo de socialização que ocorre tanto na infância, quanto na vida adulta dos indivíduos, como indicamos no terceiro capítulo desta dissertação (ALMOND; POWEL, 1989, p.47-49). 
Desta forma, não é possível avaliar o porquê destes dados positivos no caso dos membros do CONSUL, pois não dispomos de informações suficientes sobre o processo de socialização dos mesmos. Ainda assim, algumas considerações sobre a natureza da atividade destes militantes no interior do Conselho podem ser interessantes, pois este se apresenta como uma agência de socialização política central na vida destes homens e mulheres.

No seu interior, os indivíduos, por estarem submetidos constantemente a experiências políticas de caráter reivindicativo e contestador - como aquelas que descrevemos na seção anterior tenderiam a desenvolver uma percepção sobre si mesmos, como atores políticos relevantes.

É importante destacar, que os últimos parágrafos não pretendem afirmar a existência de uma relação causal entre o desenvolvimento de um sentimento de eficácia e a atividade aconselhamento, mas apenas sugerir que estas ações e mobilizações cotidianas possuem uma função pedagógica que não pode ser facilmente desprezada neste tipo de pesquisa.

Podemos afirmar, então, que estes indivíduos, de maneira diferente do que se verifica como tendência na cultura política nacional, possuem uma eficácia política subjetiva bastante desenvolvida. Como levantamos, esta auto-avaliação positiva pode estar relacionada - ainda que não exista base empírica para a comprovação -, além de entre outros fatores ligados à questão da socialização política, às experiências políticas proporcionadas pelas atividades do conselho, que funcionaria como um ambiente de formação do ativista, fazendo com que este abandone o cinismo político e se entenda como "ator relevante".

Em decorrência do exposto, acreditamos ser possível definir provisoriamente a cultura política deste grupo de ativistas, como dotada de orientações políticas significativamente compatíveis com a democracia, ao menos, em sua dimensão abstrata, com uma ênfase especial ao impulso participacionista que se manifesta objetivamente em ações concretas.

A partir deste ponto, pretendemos analisar os resultados obtidos através do questionamento sobre o nível de confiança e adesão dos entrevistados em relação às principais instituições políticas 
democráticas. O contraste entre esta dimensão da cultura política com as apresentadas nas seções anteriores, como ficará evidente, é significativo.

O primeiro objeto de nossas indagações foi o voto, entendido aqui como uma instituição política. Perguntamos sobre a sua importância como forma de participação, para o que encontramos $76,9 \%$ das respostas na opção "é muito importante", ou seja, uma distribuição explicitamente favorável à conclusão de que existe umả adesão explícita a esta instituição democrática central.

Entretanto, tal raciocínio seria precipitado, se não questionássemos também a percepção dos entrevistados sobre a maneira como esta instituição tem sido utilizada e as condições para a sua efetivação.

Neste sentido, perguntamos acerca da capacidade da população para bem votar, encontrando uma distribuição que contradiz este alto índice de adesão. Mais de $60 \%$ dos entrevistados "concordaram muito" ou "concordaram" com a seguinte afirmação: "O povo não tem capacidade para votar bem e não sabe escolher os melhores candidatos para governar o país".

Mesmo entre aqueles que afirmaram ser o voto "muito importante", $65 \%$ concordaram com a sentença, o que torna inconsistente a adesão a esta instituição ao menos no seu plano concreto, uma vez que não acreditam na real efetividade da mesma. Apesar de importante no plano abstrato, o voto é visto apenas como um procedimento desprovido de conteúdo, aparentemente em virtude do despreparo dos eleitores.

Entretanto, a postura elitista manifesta por esta avaliação negativa da capacidade de bem votar do eleitorado, é minimizada com respostas mais positivas a questões acerca da possibilidade de participação apresentada anteriormente.

Esta aparente contradição com relação à adesão à instituição do voto e à avaliação negativa da capacidade política do eleitor, na realidade reflete uma especificidade bastante interessante do grupo. Ao nos depararmos com estes dados, precisamos ter em mente que os entrevistados fazem parte de um grupo organizado em torno de um conselho popular; que tem como principal bandeira a participação direta 
(a população na condução da política municipal. O fato de acreditarem qui o cleitor nĩo sabe votar não impede nossos entrevistados de alirmarcm. na sua maioria, que este mesmo cidadão pode e deve participar eficientemente de outras maneiras. Em especial no que diz respeito à principal área de atuação do CONSUL, ou seja, política pública de saúde local, a crença de que a população pode participar de maneira eficaz se assenta na idéia de que quanto mais próximo o assunto for do ator político, mais este terá condições para participar.

Esta discussão nos remete para uma questão interessante dentro do debate acerca da possibilidade da participação nas democracias contemporâneas, muito presente na ideologia participacionista: o questionamento da dimensão técnica do debate político.

Através de observações em reuniões e discussões no interior do Conselho, identificamos que a política, em suas mais variadas dimensões, mas em especial no seu nível local, é entendida pelos membros do grupo investigado como atividade em que o conhecimento técnico opera como uma barreira à participação das camadas populares. Sobretudo, no que diz respeito à política pública de saúde, objeto por excelência de suas lutas, o confronto entre a autoridade técnica de médicos e enfermeiros e a autonomia dos representantes populares fica bastante evidente na própria definição sobre o que é saúde.

Definir a saúde apenas como ausência de doença implicaria a tecnificação do tema, o que nitidamente dificultaria a participação da população usuária dos serviços médicos na definição da política pública municipal do setor. Contra esta tendência, os movimentos sociais da área de saúde, no qual incluímos o CONSUL, têm como uma de suas principais bandeiras a defesa de um conceito de saúde que envolva uma gama infinita de questões, que vão do saneamento básico à educação de qualidade, criando o conceito de "vida saudável". Obviamente, através desta definição ampla, que questiona a centralidade do saber médico oficial, os indivíduos teriam condições ótimas de participação, pois estes é quem têm informações suficientes sobre a realidade global de seus bairros para subsidiarem ações públicas eficientes.

Procurando aprofundar esta questão no que diz respeito ao processo político no interior do Conselho, formulamos a questão, "O Sr. (a). acha que para participar do conselho a pessoa deveria ter algu- 
ma formação técnica?", para a qual obtivemos $77 \%$ de respostas negativas, o que sugere a adoção de uma postura crítica com relação à tecnificação.

Temos então a valorização acentuada de formas de aprofundamento das instituições democráticas não-representativas, em especial em direção às práticas participacionistas através de mecanismos como os Conselhos.

Caminhando nesta mesma direção, passemos agora à análise sobre a confiança e adesão às demais instituições, que, como veremos, reforça a idéia apresentada acima.

A existência de partidos, de acordo com a teoria contemporânea da democracia, é fundamental para a caracterização de um regime como democrático ou não. Assim sendo, a análise sobre o nível de confiança depositada nesta estrutura de inputs é de fundamental importância para este estudo.

Os resultados obtidos, como demonstra a tabela abaixo (Tabela 7), são bastante alarmantes, colocando este grupo de ativistas políticos no mesmo patamar que a população em geral, que, de acordo com pesquisas nacionais, compartilha uma desconfiança generalizada para com esta instituição.

\begin{tabular}{|lcc|}
\hline Tabela 7 - Grau de Confiança nos \\
\multicolumn{3}{c|}{ Partidos Políticos } \\
\hline RESPOSTAS & $\%$ & $\mathrm{~N}$ \\
Confiamuito & 3,8 & 1 \\
Confia & 19,2 & 5 \\
Confiapouco & 46,2 & 12 \\
Nãoconfia & 30,8 & 8 \\
TOTAL & 100,0 & 26 \\
\hline
\end{tabular}

Nota-se que esta avaliação negativa está intimamente associada à quebra de expectativas concretas, ou seja, um desempenho pouco eficiente dos partidos no atendimento de demandas dos indivíduos é um dos elementos explicativos fundamentais para a desconfiança na instituição.

Corroborando esta desconfiança, tratamos de verificar as percepções destes indivíduos para com os políticos em geral. Como os 
percentuais abaixo mostram, a classe política é também pouco confiável para os membros do grupo investigado.

\begin{tabular}{|c|c|c|}
\hline RESPOSTAS & $\%$ & $\mathrm{~N}$ \\
\hline Confiamuito & 4,0 & 1 \\
\hline Confia & 20,0 & 5 \\
\hline Confiapouco & 36,0 & 9 \\
\hline Não confia & 40,0 & 10 \\
\hline TOTAL & 100,0 & 25 \\
\hline
\end{tabular}

O quadro permanece inalterado quando o objeto das orientações políticas subjetivas é o governo, ou seja, a instituição democrática que é tanto responsável pelos encaminhamentos quanto pelos atendimentos de demandas.

$\mathrm{Da}$ bateria de questões que procuraram averiguar o índice de confiança e legitimidade das instituições que compõem o poder executivo na democracia, a primeira segue o mesmo padrão das formuladas anteriormente sobre os partidos e a classe política. Perguntamos em prol de quem o Brasil tem sido governado, para o qual obtivemos a seguinte distribuição: $26,9 \%$ afirmaram que a nação é administrada em benefício dos vários grupos organizados politicamente, enquanto $73,1 \%$ declaram que os grandes interesses de poucos é que são privilegiados na condução dos assuntos públicos.

Esta afirmação é corroborada com a resposta à pergunta sobre $o$ índice de confiança, pois $76,9 \%$ dos entrevistados declararam não confiar no governo. Temos então que, mesmo neste grupo de ativistas políticos organizados em uma instituição que trava contatos diários com a administração pública municipal e estadual, a desconfiança é muito acentuada.

Como afirma a teoria da cultura política, esta postura é extremamente desfavorável à consolidação de um regime democrático, pois gera um enfraquecimento perigoso de suas instituições que podem ser ameaçadas por ameaças externas e internas. 
Parte desta desconfiança generalizada pelas instituições políticas pode ser explicada, de acordo com MOISÉS (1995), por sucessivas gestões administrativamente ineficazes no atendimento às demandas da população.

Elementos interessantes para nossa análise surgem quando propomos uma comparação entre estes níveis de confiança entre instituições representativas e participativas. Neste sentido, interrogamos os membros do Consul sobre o nível de confiança nos deputados e senadores, no executivo, nos partidos políticos e - a fim de estabelecer uma comparação - nas organizações não-governamentais, nas quais a participação tende a ser direta.

\section{Tabela 9 - Grau de Conflanģa nas Institulgóes Politicas}

\begin{tabular}{l|cc|cc|cc|cc|c} 
& Confia muito & \multicolumn{2}{|c|}{ Confila } & Confia pouco & Não confia & \\
CâmaraeSenado & $\%$ & $\mathbf{N}$ & $\%$ & $\mathbf{N}$ & $\%$ & $\mathbf{N}$ & $\%$ & $\mathbf{N}$ & TOTAL \\
Executivo & 0,0 & 0 & 23,1 & 6 & 42,3 & $\mathbf{1 1}$ & 34,6 & 9 & 100,0 \\
Partidos politicos & 3,8 & 1 & 0,0 & 0 & 19,2 & 2 & 76,9 & 20 & 100,0 \\
Ong's & 3,8 & 1 & 19,2 & 5 & 46,2 & 12 & 30,8 & 8 & 100,0 \\
& 31,8 & 7 & 40,9 & 9 & 22,7 & 5 & 4,5 & 1 & 100,0
\end{tabular}

Nota: 4 dos entrevistados não souberam responder com relação às Ongs

Como aparece de maneira muito clara neste quadro, nas instituições ou grupos que representam a dimensão representativa da democracia, verifica-se uma concentração da maioria das opiniões entre as opções "confia pouco" e "não confia", enquanto que - a título de comparação - temos uma inversão quando o alvo das percepções são organizações que se colocam como alternativas à forma representativa de participação política, aqui representados pelas Ongs.

É importante destacar que esta desconfiança em relação às instituições políticas não é um fenômeno que se manifesta apenas no Brasil. Como a Tabela 10 demonstra, encontramos percentuais bastante elevados em praticamente todos os países americanos, inclusive nos Estados Unidos da América. Em especial no que diz respeito aos partidos políticos, uma das instituições representativas fundamentais, encontramos a expressiva média de $85 \%$ de desconfiança. 
Tubda 10 - Conilanga nas lnstituigóes na América

(\% confia pouco ou não confia)

\begin{tabular}{l|c|c|c} 
& TRIBUNAIS & CONGRESSOS & PARTIDOS \\
Argentina & 81 & 81,5 & 89,8 \\
Bolivia & 78 & 72,9 & 88,0 \\
Brasil & 65,1 & 87,4 & 88,3 \\
Chile & 70,4 & 67,7 & 78,6 \\
Colômbia & 62,8 & 67,8 & 84,0 \\
CostaRica & 43,9 & 60,9 & 76,3 \\
RepúblicaDominicana & 67,0 & 72,9 & 84,5 \\
Equador & 88,0 & 91,0 & 92,8 \\
Estados Unidos & 40,4 & 42,6 & 60,8 \\
Guatemala & 80,6 & 78,1 & 84,2 \\
México & 71,1 & 68,0 & 77,7 \\
Panamá & 70,1 & 80,1 & 84,5 \\
Paraguai & 77,0 & 76,8 & 87,9 \\
Peru & 74,6 & 77,2 & 77,9 \\
Venezuela & 73,6 & 82,7 & 91,2 \\
Média & 72,0 & 76,0 & 85,0 \\
Fonte: Encuesta Panamericana(1998) & & &
\end{tabular}

Como apontamos no início desta seção, podemos identificar uma discrepância entre, de um lado, os dados referentes à adesão aos valores democráticos e a eficácia política subjetiva, apresentados nas seções anteriores, e, de outro, aqueles que se referem à adesão e confiança nas instituições. É justamente nesta contradição estabelecida pelos dados levantados que nos concentraremos para analisar as relações entre a cultura política e a teoria da democracia.

\section{Participacionismo e Crítica}

Neste momento, iremos propor uma análise sobre o conjunto dos dados apresentados anteriormente, apresentando uma explicação para a contradição entre as orientações políticas subjetivas dirigidas aos diferentes objetos políticos. Como antecipamos em vários momentos, nossa tese é que esta contradição tem uma raiz teórica.

O primeiro elemento que compõe este quadro contraditório é a 
existência de uma adesão relativamente forte do grupo investigado aos valores democráticos na sua dimensão abstrata. Isto se manifestou por uma postura relativamente participacionista, com índices de eficácia política subjetiva significativos associados a uma tendência anti-elitista, que coloca os membros do Conselho em uma posição diferenciada em relação ao conjunto da população nacional, que, como afirmam pesquisas citadas anteriormente, compartilham uma auto-avaliação negativa sobre o seu papel político. Estes elementos contribuem para a caracterização da cultura política do grupo como, no múnimo, favorável à democracia.

Porém, levando à complexificação da análise, temos dados que se opõem à tendência que vinha se manifestando, pois, no que se refere à confiança nas instituições políticas, os entrevistados manifestaram a mesma posição expressa pela população em geral, ou seja, uma desconfiança generalizada (MOISËS, 1995).

Esta contradição, recorrente nos estudos sobre cultura política realizados no Brasil nos últimos anos, tem sido explicada de duas maneiras diferentes pela literatura. Iremos apresentar cada uma destas explicações para, em seguida, propor uma terceira possibilidade que traz como diferencial uma outra concepção sobre o regime democrático, que não se detém apenas sobre sua dimensão procedimental.

Partilhando da primeira explicação, temos aqueles pesquisadores que, recorrendo à terminologia de Easton (1968), identificam a existência de dois tipos de apoios ao regime político, um difuso e outro específico.

No primeiro tipo, estariam aquelas percepções que dizem respeito ao sistema de maneira genérica, ou seja, no nível dos valores mais gerais que o sustentam. No caso do presente estudo, poderíamos dizer que o grupo apóia de maneira difusa a democracia.

$\mathrm{Na}$ segunda espécie de apoio, estariam as percepções que envolvem avaliações e adesão às instituições concretas do regime. Neste nível os entrevistados demonstraram um baixo apoio específico à democracia, expresso através da desconfiança acentuada.

Com esta distinção, a contradição entre a adesão a valores democráticos e a desconfiança para com as suas instituições concretas estaria solucionada, pois o fato de os indivíduos compartilharem de um 
conjunto determinado de valores, não os obriga a avaliar positivamente situações conjunturais. Ou seja, um baixo apoio específico pode conviver com um apoio difuso elevado, sem que o regime democrático seja imediatamente abalado.

Isto ocorre porque a adesão difusa é construída através de um processo de socialização mais prolongado e que tem raízes profundas que não são diretamente abaladas por avaliações negativas de desempenho administrativo de um governo ou de outro.

Entretanto, os autores que apontam para esta solução também destacam o perigo que a permanência desta oposição entre os dois tipos de apoio pode acarretar para a manutenção do regime político, pois sucessivas avaliações negativas das instituições podem, no longo prazo, minar também a crença nos valores gerais que o sustentam.

$\mathrm{O}$ que queremos destacar aqui é que, apesar da coexistência destes dois posicionamentos - de adesão e de crítica - o baixo apoio específico é entendido nesta explicação como um problema que pode vir a minar as bases da democracia. Problema que deve ser contornado por ações eficazes dos governos que possam colaborar para a compatibilização da adesão abstrata e concreta com o sistema.

Também caminhando nesta direção, encontramos a segunda explicação, presente originalmente em Dahl (1997, p.144-415) que, trabalhando com o conceito de eficácia, identifica que um dos traços fundamentais da crença dos ativistas políticos é a expectativa, positiva ou não, de que determinado regime irá solucionar problemas críticos.

Uma postura positiva diante da performance de governos seria, de acordo com este autor, herdada pelas novas gerações, através de um processo de socialização. Para comprovar tal afirmação apresenta dados sobre o nível de expectativa quanto ao desempenho governamental de jovens norte-americanos, que avaliam positivamente a capacidade de seus governantes para solucionarem crises.

Esta avaliação, entretanto, pode ser alterada - assim como todos os demais elementos que compõem a cultura política - por contatos diretos com o sistema político, neste caso experiências positivas ou negativas quanto à performance governamental.

Assim, mesmo socializados na crença de que o governo é eficaz, indivíduos que sucessivamente sofrem por ingerências de seus representantes possivelmente deixam de confiar na ação governamental. 
Como esperamos ter deixado claro, é extremamente negativa para a estabilidade de um sistema político, a existência de avaliações negativas, mesmo que se refiram à dimensão objetiva da eficácia governamental, porquanto sucessivas avaliações desfavoráveis neste quesito podem, gradualmente, minar a adesão dos indivíduos às demais crenças que compõem a totalidade de suas orientações políticas subjetivas.

Como escreve Dahl, a socialização constrói sempre uma reserva de expectativa positiva para os momentos de crise do sistema, uma vez que todos os governos, vez ou outra, falham. Estas reservas, porém, como o próprio termo revela, são finitas, o que é ainda mais verdade quando se trata de regimes novos.

Transpondo este raciocínio para a análise da situação brasileira, Moisés (1995) verifica que a legitimidade da democracia em sua dimensão geral está relativamente sedimentada no cenário nacional, o que não impede a existência de índices alarmantes de desconfiança nas instituições que representam esta forma de governo, graças a performances insuficientes dos ocupantes dos cargos públicos diante dos problemas estruturais por que passamos.

Esta situação, entretanto, no curto prazo, não traria problemas para nossa recente democracia, pois o autor identifica a existência de uma reserva preliminar de legitimidade. Esta reserva seria a responsável por afastar a avaliação negativa do desempenho de personalidades ou instituições da adesão à democracia como conjunto de valores gerais.

$\mathrm{O}$ fato é que, pelo caráter finito da reserva, a desconfiança aparece como um obstáculo para a consolidação, ainda que no curto prazo a democracia não esteja em xeque.

Se seguíssemos esses passos, reforçaríamos o argumento de que este reservatório de expectativa estaria assegurando, apesar das avaliações negativas quanto ao desempenho, uma adesão aos demais valores democráticos, como verificamos na primeira seção deste artigo. Nos ativistas do CONSUL, teríamos um exemplo de como esta reserva evita um desgaste das demais dimensões da cultura política. Ainda assim, mesmo neste grupo ativista e participacionista, a desconfiança nas instituições se revestiria de um caráter negativo e perigoso, ao menos no médio e longo prazo. 
Entretanto, neste estudo acreditamos que estes equacionamentos não sejam tão frutíferos assim, visto que o próprio caráter militante do grupo por nós investigado nos leva a acreditar que por mais negativas que fossem as avaliações de desempenho, ou menores que fossem os índices de apoio específico, eles tenderiam a permanecer expressando as percepções que apresentaram.

Na realidade, somos levados a crer que a permanência desta contradição tende a, cada vez mais, reforçar as opiniões expressas pelos entrevistados, sobretudo com relação àqueles questionamentos que nos direcionaram a entender o grupo como participacionista, tais como a seu interesse por política e sua eficácia política subjetiva. Em resumo, acreditamos que a permanência de uma efetiva incapacidade administrativa dos representantes eleitos em solucionar crises tende a reforçar as percepções dos entrevistados sobre a importância da participação da população através de canais alternativos como conselhos, movimentos sociais, plebiscitos, etc.

Isto porque, de acordo com os dados apresentados, a relativa insatisfação com as instituições representativas democráticas, por parte dos membros deste Conselho, estão acompanhadas por uma adesão à outra forma de entender o regime. Neste sentido, estas avaliações e percepções negativas devem ser entendidas como defesas da participação da população por outros canais.

Se a noção de apoio específico/difuso ou a de reservatório de expectativa fossem por nós utilizadas, a contradição se explicaria e seríamos levados a identificar que, prosseguindo este processo, a democracia tenderia a atravessar dificuldades quanto à legitimidade junto aos seus cidadãos.

Inevitavelmente, estes caminhos levam à noção de crise do regime, através da via corrosão das orientações políticas subjetivas mais abstratas a partir da baixa avaliação do desempenho governamental.

Em nosso ponto de vista, esta conclusão é própria de análises que seguem o que denominamos na primeira seção deste artigo de teoria realista ou enfatizadora da dimensão representativa da democracia. Se o regime é entendido apenas na sua dimensão formal, ou procedimental como definiu Schumpeter (1961), a proposta de um 
desenvolvimento alternativo para a democracia, centrado na relevância de canais diretos de participação, defendida por uma elite popular, realmente perde muito de sua força.

Sendo assim, a consideração sobre uma crítica às formas representativas e a valorização da capacidade de participar diretamente do processo decisório da democracia, escapa do modelo de análise empirista desta teoria da democracia.

Não estamos questionando a fecundidade de tal abordagem para estudos sobre a população em geral, em especial no caso brasileiro, onde a história nos dá inúmeros trágicos exemplos de situações em que a população aderiu a regimes autoritários. Nestes casos, acreditamos que esta desconfiança pode sim ser interpretada como um perigo em virtude de nossa pequena experiência democrática. Estamos apenas afirmando que, em se tratando de grupos de ativistas com uma orientação democrática, como o estudo aqui apontou, uma outra interpretação pode ser construída. Trata-se, portanto, de um simples questionamento sobre a aplicação universal dos pressupostos clássicos da teoria da cultura política a todos os níveis em que tais estudos se aplicam.

Desta forma, para nosso estudo, acreditamos que seja fundamental operar uma junção entre o realismo e o participacionismo democrático. É óbvio que as análises realistas são extremamente frutíferas para estudos sobre cultura política, pois definem claramente os marcos institucionais para os quais se dirigem as orientações políticas dos atores políticos, entretanto, o participacionismo pode permitir uma consideração importante sobre as expectativas destes mesmos personagens.

Assim, se consideramos em nossa análise a possibilidade de avançar para além do realismo, identificaremos uma postura em nossos entrevistados muito próxima do que podemos denominar de participacionista e crítica. Neste caso, a contradição entre adesão a valores democráticos no plano mais geral e desconfiança quanto aos ocupantes do governo não aparece como sintoma perigoso para o regime. Dentro de um grupo com uma visão de mundo democrática, tal como o estudado nesta pesquisa, uma desconfiança ou crítica às instituições representativas não representam diretamente um risco ou perigo para a democracia na sua totalidade. 
Na realidade, dentro desta perspectiva, tal situação emerge como um reforço deste regime, que na subjetividade dos entrevistados extrapola seus limites formais e caminha em direção ao aprofundamento da participação, marca distintiva da democracia.

Dentro do paradigma "realista" toda e qualquer crítica às instituições representativas, é logo interpretada como expressão de uma cultura política autoritária, quando podem ser tão somente a expressão de um descontentamento, o que na realidade brasileira é bastante plausível.

Acreditamos que as análises que buscaram resolver a contradição entre adesão a valores democráticos e desconfiança para com as instituições através de conceitos como "apoio difuso/ específico" ou "reserva preliminar de legitimidade", por adotarem um conceito enfatizador da dimensão representativa da democracia fecharam os olhos para um fato marcado pela obviedade: a crítica das instituições representativas não é necessariamente expressão de autoritarismo político.

Se adotarmos este expediente alternativo e não limitarmos nossa compreensão sobre a democracia a esta dimensão formal, a democracia deixa de estar "em xeque" no médio e longo prazo. Esta mudança de perspectiva teórico-conceitual pode nos fazer enxergar que o jogo democrático apenas começou, ou melhor, recomeçou. 


\section{Referências Bibliográficas}

ALMOND, Gabriel; POWELL JR, Bingham G. Uma teoria da Política Comparada. Rio de Janeiro: Zahar, 1972.

ALMOND, Gabriel; VERBA, Sidney. The Civic Culture: political attitudes and democracy in five nations. Nova York: Sage, 1989.

BACHRACH, Peter. The Theory of Democratic Elitism: a critique. Boston: University Press of America, 1967.

CARVALHO, J. Murilo. O motivo endêmico no imaginário social brasileiro. In: PANDOLFI, Dulce C. et al. (Orgs). Cidadania, justiça e violência. Rio de Janeiro: Fundação Getúlio Vargas, 1999.

DAHL, Robert. Poliarquia. São Paulo: Edusp, 1997.

DOWNS, Anthony. Uma teoria econômica da democracia. São Paulo: Edusp, 1999.

EASTON, David. Uma teoria de análise política. Rio de Janeiro: Zahar, 1968.

LIMA, M.Regina Soares; CHEIBUB, Zairo B. Instituições e valores : as dimensões da democracia na visão a elite brasileira. Revista Brasileira de Ciências Sociais, São Paulo, n.31, p.83-110, 1996.

MILL, J.Stuart. Considerações sobre o Governo Representativo. Brasília: UnB, 1981.

MOISÉS, J.A. Os brasileiros e a democracia (bases sócio-políticas da legitimidade democrática). São Paulo: Ática, 1995.

MOUFFE, Chantal. O regresso do político. Lisboa: Gradiva, 1996.

PATEMAN, Carole. Participação e reoria democrática. Rio de Janeiro: Paz e Terra, 1992.

SARTORI, Giovanni. A reoria da democracia revisitada. São Paulo: Ática, 1994.

SCHUMPETER, Joseph. Capitalismo, socialismo, democracia. Rio de Janeiro: Fundo de Cultura, 1961. 


\section{Abstract}

This artice talks about the troubled relation between the present theory of democracy and the studies about Political culture. It is based in a study made in a popular organization (CONSUL- Londrina's regional health Concil) about their subjective political opinions. We intend to show that the thesis borught up by a study made with a subgroup in the national community thend to have their points of view changed in a theorical debate about democracy.

Key-words: democracy, political culture, participation, advices. 